\title{
Household food security among Hadza hunter-gatherers in Mkalama district, Tanzania
}

\author{
John Godfrey Safari ${ }^{* *}$, Aron Joseph Nkua² and Zacharia Samwel Masanyiwa²
}

\begin{abstract}
Background: Food insecurity is a widespread public health concern in many communities of sub-Saharan Africa. This study involved the Hadza hunter-gatherers of Tanzania, the only ethnic group in the country that has traditionally subsisted on hunting and gathering. In recent years, however, these communities have adopted mixed foraging economies. Information on how this change affects household food security is rather limited. The aim of this study was to assess the status of food security and the factors influencing household food security in the Hadza hunter-gatherer communities.

Methods: A cross-sectional study of 200 households was conducted in Mkalama district, Tanzania. Sampled householders represented individuals whose livelihood is mainly dependent on foraging $(n=129)$, beekeeping $(n=30)$ and farming $(n=41)$. Food security was measured by assessing food availability (Months of Adequate Food Provisioning (MAHFP)), food access (Household Food Insecurity Access Scale (HFIAS)) and food utilization (Dietary Diversity Scores (DDS)).
\end{abstract}

Results: Mean MAHFP was lower $(p=0.000)$ in predominantly foraging households $(8.4 \pm 1.1)$ compared with those involved in beekeeping (8.7 \pm 1.6$)$ or farming (9.6 \pm 1.9$)$. Based on HFIAS indicator, the prevalence of food insecurity varied with the household's main activity (83.0\% foraging, $46.7 \%$ beekeeping and $26.8 \%$ farming). Further, regression analyses show that the farming households were more likely to be food secure than the foraging households $(\mathrm{OR}=10.7, p=0.01)$. Dietary diversity scores also varied significantly with household's main activity. About $65 \%$ of households (86\% foraging, $63.3 \%$ beekeeping and $2.4 \%$ farming) consumed diets below the critical value of $\leq 4$ food groups $24 \mathrm{~h}$ prior to survey. Social demographic characteristics and livelihood options are strong predictors of household food security.

Conclusion: All indicators used to assess food security point to high level of food insecurity in households mainly subsisting on foraging compared with beekeeping and farming. The primary dependence on foraging is associated with a longer period of food shortage, high prevalence of food insecurity conditions and low consumption of food varieties. Livelihood diversification coupled with provision of agricultural support services is necessary for the development of a secure future of the Hadza communities.

Keywords: Hadza, Hunter-gatherers, Food availability, Food access, Food utilization

\section{Introduction}

The state of food insecurity remains high in poor countries [1], and seems to be most severe in sub-Saharan Africa [2]. Food insecurity negatively affects human

*Correspondence: john.safari@mocu.ac.tz

${ }^{1}$ Moshi Co-operative University, P.O. Box 474, Moshi, Tanzania

Full list of author information is available at the end of the article physical, social, emotional, and cognitive development throughout the life course [3]. In contrast, food security exists when all people, at all times, have physical, social and economic access to sufficient safe and nutritious food that meets their dietary needs and food preferences for an active and healthy life [4]. It can be achieved through consecutive pathways namely food availability, food access and food use [5]. The conception of food 
security overarch perspective on raising food production in addressing a complex array of social and ecological problems related to under-consumption and hunger [6]. For traditional societies, strategies have historically relied on a wide variety of foods and diversification of activities related to food procurement as exemplified by savagery or foraging $[7,8]$. A historic account also shows that hunting and gathering has been a successful human subsistence strategy because it maximizes food security through diverse food targets [9-12].

The Hadzabe (pl.; Hadza, sing.) of Tanzania (also known as Hadzapi, Hatsa, Tindiga, Kindiga, and Kangeju) present the only ethnic group that has traditionally subsisted on hunting and gathering in the country $[13,14]$. This community is known for being reliant on hunting game, collecting honey, digging tubers and gathering berries and other wild fruits [15-18]. However, local incursions by non-Hadza pastoral and agricultural groups are recorded in historic times as early as the beginning of the twentieth century to affect the foraging environment [19]. Studies show that large areas of former bush that once provided wild foods are now being used for farming and pastoral activities [20,21]. This situation has resulted in mixed foraging economies which are characterized by decreasing reliance on wild foods and the development of more agriculturally dependent economy [10]. While food security clearly depends on agricultural conditions and food production, it also depends on socio-economic conditions including the distribution, access and affordability of food [22]. There is, however, limited information on how shifts in the livelihoods of the contemporary huntergatherers have affected household food security. Besides, food systems are not fixed but are in a constant state of transformation $[23,24]$. The objectives of this study were (i) to examine the household choices of main livelihood options (ii) to assess the status of household food security and (iii) to determine the factors affecting household food security. Knowledge on these aspects is crucial in designing interventions that aim to address food security challenges facing the contemporary hunter-gatherers.

\section{Methods}

\section{Study area}

This study was conducted in Munguli village, Mwangeza ward in Mkalama District in Tanzania. The study area experiences a warm and dry climate with mean annual temperatures ranging from 25 to $30^{\circ} \mathrm{C}$. The mean annual rainfall ranges from 300 to $600 \mathrm{~mm}$. The rains mainly fall between December and May [25]. The area consists of a mixture of savanna grasslands, woodlands, and deciduous bushlands and shrub lands [26]. Further, information obtained from the village office indicated that at the time of conducting this study, the area had a total of 419 households distributed in four sub-villages as follows: Kipamba (130 households), Munung'una (111), Midembwi (103) and Mwazururaji (75). Residents in these areas are traditionally foragers who are currently involved in various forms of livelihoods including foraging, beekeeping, farming, and trade. The term 'forager' is a more generic name for 'hunter-gatherer' [27]. In this study, the two terms are used interchangeably.

\section{Data collection}

Data were drawn from 200 households in a cross-sectional survey carried out between May and August, 2017. A household was defined as a group of people who sleep under the same roof and take meals together. The study involved a combination of focus group discussions, key informant interviews and household survey. Household selection was based on random sampling procedures based on the official list of households obtained from village leaders. The sample size was estimated through a proportionate sampling technique described in Miah [28] as follows:

$$
\begin{aligned}
& n=\frac{N \sum N_{h} P_{h} Q_{h}}{N^{2} D^{2}+\sum N_{h} P_{h} Q_{h}} \\
& n_{h}=\frac{N_{h}}{N} * n
\end{aligned}
$$

where $n=$ total sample size, $n_{h}=$ Sample size for $h$ stratum (village), $N=$ total population (419), $N_{h}=$ population size of $h$ stratum, $P_{h}=$ proportion of households involved in foraging, beekeeping or farming as their primary livelihood activity in $h$ stratum (0.5), $Q_{h}=1-P_{h}$, $D=\mathrm{d} / \mathrm{z}, d=$ precision (error). Using value for $d=0.05$, $z=1.96$ (95\%, confidence interval), substituted in Eq. 1, the sample size obtained was 200 households. The proportionate sample size of households living in each subvillage was calculated using Eq. 2 as follows: Kipamba (62 households), Munung'una (53), Midembwi (49) and Mwazururaji (36). The research project was approved by the research committee at the Institute of Rural Development Planning. Interviews were conducted in Kiswahili, the National language in Tanzania. The responses were then translated into English. The survey was administered to the household head or a responsible adult in the household who could respond on behalf of the entire household. According to Barrett [29], food security is based on three pillars: availability, access, and utilization. This is a hierarchical classification because availability is necessary but not sufficient to guarantee access, while access itself is necessary but not sufficient to assure effective utilization. A large variety of indicators for assessing 
food security have been proposed [30]. This study focuses on the three pillars with a set of selected indicators as detailed in the following sub-sections.

\section{Food availability}

Food availability refers to the sufficiency of a food supply to meet people's needs [31]. In this study, food availability was indirectly assessed by inquiring the extent to which wild food resources could be obtained for the household needs. The availability of important wild food resources was rated as $1=$ very low, $2=$ low, $3=$ high or $4=$ very high. Household food availability meant food obtained through cultivation in the field and collection from the wild environment, and was assessed through Months of Adequate Food Provisioning (MAHFP) 12 months preceding the survey. This indicator refers to the number of months per year that households report no food shortages.

\section{Food access}

To measure food access, the Household Food Insecurity Access Scale (HFIAS) based on a household's recent experiences of food insecurity were used as indicators of Household Food Insecurity (HFI) as described earlier [32]. The HFIAS guideline was used to review questions in order to suit the local context and ensure that the questions were understood correctly. A total of nine food insecurity conditions were inquired. These conditions were whether four weeks preceding the survey the respondent or any member of the family worried about food, unable to eat preferred foods, ate a few variety of foods, ate food they did not want to eat, ate smaller meal and ate fewer meals in a day. Others were no food of any kind in the household, went to sleep hungry or went day and night without food. As described in the HFIAS guideline, these indicators provide summary information on the prevalence of households experiencing one or more behaviours in each of the three domains reflected in the HFIAS namely anxiety and uncertainty, insufficient quality and insufficient food intake and its physical consequences [32]. Each indicator was given 1 point of score for each form of food insecurity that a household experienced or zero if a given form of food insecurity was not experienced. An affirmative answer was then followed by a frequency-of-occurrence question to determine if the condition happened rarely (once or twice), sometimes (3-10 times), or often (>10 times) during the reference period.

\section{Dietary diversity}

Dietary diversity was measured in terms of dietary diversity scores (DDS), a common indicator that counts the number of food groups consumed over a certain period of time [33]. It is one of a priori defined diet quality indices used to assess nutrient adequacy, and has been positively associated with the number of different foods consumed [34]. High food variety is regarded to be necessary for an adequate nutrient intake, to lessen the chances of deficient or excessive intake of single nutrient [35]. In this study, respondents were asked to recall all the dishes they had consumed in the previous $24 \mathrm{~h}$. Food items were categorized into 12 different food groups. These were cereals, tubers, legumes, meat, egg, vegetables, fruits, oil, sweets, milk, fish and sugar or honey. Each food group counted toward the household score adding " 1 " if any family member consumed a food item from the group.

\section{Statistical analysis Livelihood options}

In respect of the livelihood options, data were fitted to a Multinomial Logit (MNL) model to estimate the significance of the factors that influence a household's choice of the main activity. The model is expressed in Eq. 3 as follows:

$$
\operatorname{Pr}[Y i=j]=\frac{\exp \left(\beta_{j}^{i} X_{i}\right)}{\sum_{j=0}^{j} \exp \left(\beta_{j}^{i} X_{i}\right)}
$$

where: $\operatorname{Pr}\left[Y_{i}=j\right]$ is the probability of choosing foraging or farming with beekeeping as the reference category; $j=$ is the number of possible activities; $j=0=$ beekeeping; $\mathrm{X}_{i}$ is the vector of the predictor variables and $\beta_{j}$ is a vector of the estimated parameters. Since logit model uses logarithmic transformation to assume linearity of the outcome variables on the explanatory variables, the specific logit model to predict the odds of activity choice is given in Eq. 4.

$$
\ln \left(\frac{\mathcal{P}}{1-\mathcal{P}}\right)=\beta_{0}+\sum_{i=1}^{n} \beta_{i} X_{i}+\varepsilon_{i}
$$

where $n$ is the total number of variables, $\beta_{i}$ is the regression constant, $X_{i}$ is the logit coefficient for the variable and $\varepsilon$ is the error term. From Eq. 4 , the quantity $p /(1-p)$ is the odds ratio expressed as a linear function of the independent factors. Data were analysed using Statistical Social Sciences (SPSS) version 16 (SPSS Inc., Chicago, IL, USA). In the MNL analyses, several models were tested with a forward entry method. At each step, the term whose addition caused the largest statistically significant change in -2 Log Likelihood was added to the model. The final model included important predictors only. 


\section{Food availability}

Food availability involved assessment of wild foods and food obtained through crop cultivation and/or purchase. As for the wild foods, a composite index for availability of the resources was constructed as follows:

$$
I=\sum_{i=1}^{N} X_{i} \cdot W_{i} / N
$$

where, $I=$ composite index of a particular wild food, $X_{i}=$ individual wild food availability, $W i=$ respective weight for a given wild food (very low $=0.25$, low $=0.5$, high $=0.75$, very high $=1$ ), and $N=$ total number of responses. Indices show the degree of availability of important wild foods. Food obtained through crop cultivation, collection from the wild or purchase was assessed through MAHFP and compared between households mainly subsisting on foraging, beekeeping and farming.

\section{Food access}

In calculating HFIAS score, the responses on frequencyof-occurrence were coded as $0=$ never, $1=$ rarely, $2=$ sometimes, or $3=$ often. A HFIAS score variable was calculated for each household by summing the codes for each frequency-of-occurrence question. All cases where the answer was "no" were coded 0 . Thus, a possible maximum score for the household was 27 while the minimum score was 0 for households that responded "no" to all the occurrence questions. Average HFIAS score was computed as the sum of HFIAS scores in the sample/number of HFIAS scores (i.e. households in the sample). The higher the score, the more food insecurity (access) the household experienced. The lower the score, the less the food insecurity.

Further, socio-economic and demographic factors were used to predict household food insecurity. A total of nine variables were included in the regression analysis to identify the key predictors of household food insecurity. These variables were age of the respondent, sex of the household head, highest education level of the household head and household size. Others were the dependency ratio, farm size, possession of agricultural tools, involvement in wage labour and household main activity. Dependency ratio was defined as the number of dependent children $<18$ years of age plus the number of dependent elderly over 65 years of age relative to the number of working aged adults in the household [36]. Diagnostic analyses were carried out to assess the potential for collinearity among the independent variables by assessing Variance Inflation Factors (VIFs). The observed VIFs ranged from 1.3 to 2.2 which is below the cut-offs above which collinearity may be considered a problem [37].
Thus, inclusion of the separate predictors in the model is statistically valid. Dependent variable had a binary outcome: food secure household (HFIAS $\leq 17$ ) or food insecure household (HFIAS $>17$ ) as described in the FAO report [38]. Analysis of food access was also performed by assessing the relationship between food insecurity conditions and predominant household activity (foraging, beekeeping or farming) using a Chi-square test or analysis of variance. In these analyses, the significance level was set at $p<0.05$.

\section{Dietary diversity}

Dietary diversity scores (DDS) were calculated from $24 \mathrm{~h}$ recall data. These dietary diversity scores were defined as the sum of food groups (0-12) from the chosen food items. DDS was used as a response variable against independent socio-demographic factors such as age of the respondent, sex of the household head and highest education level of the household head, family size and dependency ratio. Means and standard deviation differences for DDS in households with foraging, beekeeping and farming were compared using a one way analysis of variance (ANOVA) at 95\% level of confidence. Because the responses on household's main activities were ubalanced, HFIAS scores were subjected to Welch $F$-test which is more conservative than the regular ANOVA $F$-test. This test statistic reduces the odds of commiting type I error which could result from unbalanced sample size or unequal variance.

\section{Results}

\section{Household characteristics and livelihood options}

This study involved respondents of varied socio-economic and demographic backgrounds (Table 1). Findings show that the average age of the respondents was 42 years. The majority of the respondents were males (67\%), married (70\%) and had no formal education (67\%). On average, households owned a half acre farm with eight members. All households foraged wild foods but at a varying degree of involvement. The main livelihood options were foraging (65\%), farming $(21 \%)$ and beekeeping (14\%). Households subsisting mainly on foraging regarded farming or animal husbandry as fallback strategy to support the primary dependence on wild foods. Only $32 \%$ of the surveyed households possessed agicultural tools.

Results of the multinomial logit estimation on livelihood choices among respondents are presented in Table 2. General analysis of the odds ratio values indicates lower odds ratios $(\mathrm{OR}<1)$ for most of the independent variables. The lower the odds ratio value, the lower the probability of a household with a given characteristic to change in favour of foraging or farming as 
Table 1 Summary statistics

\begin{tabular}{|c|c|c|c|c|}
\hline Variable & Min. & Max. & Mean & SD. \\
\hline Age (years) & 20 & 70 & 42.0 & 11.9 \\
\hline Sex of respondent ( 1 if male; 0 otherwise) & 0 & 1 & 0.67 & 0.4 \\
\hline Household head is married ( 1 if yes; 0 otherwise) & 0 & 1 & 0.70 & 0.5 \\
\hline Education level (1 if formal; 0 otherwise) & 0 & 1 & 0.33 & 0.4 \\
\hline Farm size (continuous) & 0 & 5 & 0.50 & 1.8 \\
\hline Household size (continuous) & 2 & 16 & 8.00 & 3.7 \\
\hline Primary occupation is foraging ( 1 if yes; 0 otherwise) & 0 & 1 & 0.65 & 0.4 \\
\hline Primary occupation is farming ( 1 if yes; 0 otherwise) & 0 & 1 & 0.21 & 0.4 \\
\hline Primay occupation is beekeeping ( 1 if yes; 0 otherwise) & 0 & 1 & 0.14 & 0.3 \\
\hline Household owns small stock (1 if yes; 0 otherwise) & 0 & 1 & 0.70 & 0.4 \\
\hline Household involved in wage labour (1 if yes; 0 otherwise) & 0 & 1 & 0.28 & 0.3 \\
\hline Household possess agicultural tools ( 1 if yes; 0 otherwise) & 0 & 1 & 0.32 & 0.4 \\
\hline
\end{tabular}

Table 2 Multinomial logit estimation for foraging and farming compared with beekeeping

\begin{tabular}{|c|c|c|c|c|c|c|}
\hline \multirow[t]{2}{*}{ Variable } & \multicolumn{3}{|c|}{ Foraging } & \multicolumn{3}{|c|}{ Farming } \\
\hline & B & $p$ & OR & $\bar{B}$ & $p$ & OR \\
\hline Household head (below 35 years) & -1.15 & 0.091 & 0.3 & 1.40 & 0.000 & 4.1 \\
\hline Household head is female & -1.14 & 0.023 & 0.3 & 1.78 & 0.000 & 5.9 \\
\hline Household head is married & 0.15 & 0.716 & 1.7 & -3.28 & 0.002 & 0.0 \\
\hline Farm size (below 3 acres) & 3.10 & 0.000 & 22.2 & -1.57 & 0.010 & 0.2 \\
\hline Household size (below 8 members) & -1.27 & 0.005 & 0.3 & 2.00 & 0.000 & 2.6 \\
\hline Dependency ratio (above 0.4) & -2.31 & 0.000 & 0.1 & 1.15 & 0.011 & 3.2 \\
\hline Household owns small stock & -1.22 & 0.037 & 0.2 & 2.57 & 0.000 & 13.1 \\
\hline Involved in wage labour & -0.89 & 0.068 & 0.4 & 1.98 & 0.038 & 7.2 \\
\hline
\end{tabular}

The reference category is beekeeping; Number of obs (200); Wald Chi2 $=182 ; \mathrm{df}=18 ; p=0.000 ;$ Nagelkerke $=0.70$

a result of changing the magnitude of an independent factor by one unit. The results reveal that farming was a more likely choice compared with beekeeping as a reference category $(\mathrm{OR}>1)$ in households whose heads were younger (below 35 years), female and where the family size exceeded eight persons with a dependency ratio greater than 0.4. Farm size of less than three acres increased the odds of foraging relative to the reference category. This variable, however, predicted lower probability of farming compared with beekeeping. Further, results show that household's choice of subsistence activity was dependent on the demographic characteristics of the household head. For instance, at the age 20-35 years, all individuals were involved in beekeeping, farming and foraging. Beyond this age range, however, beekeeping and hunting became the dominant activities. Findings also show that owning small stock decreased the odds of foraging relative to beekeeping.

\section{Food availability}

One of the essential variables to the attainment of food security is that food resources should be consistently available or within the individual's reach. The most common food resources of animal and plant origin which the Hadza consume are presented in Table 3. These include four species of animals, six species of berries, six species of tubers (includes corms, bulbs and rhizomes which normally store underground water throughout seasons) and baobab.

Findings clearly indicate limited availability of food resources especially meat $(I=0.337$ to 0.425$)$ and berries $(I=0.433$ to 0.503$)$. Berries are usually found in the wet season (December-May), baobab in the early dry season (July-August) and tubers in all seasons. Although relatively more available than other wild food resources, respondents were concerned about the declining wild food resources as one of them stated: 
Table 3 Distribution of respondents by current availability of wild food resources of animal and plant origin

\begin{tabular}{|c|c|c|c|c|c|c|c|}
\hline Type $^{a}$ & Hadza name & Botanical name & $N$ & $\begin{array}{l}\text { Very low } \\
(0.25)\end{array}$ & Low $(0.5)$ & High (0.75) & Sum of index $(I)$ \\
\hline Meat & Komati & Taurotragus oryx & 86 & 68 & 6 & 12 & 0.337 \\
\hline Meat & Nakomako & Syncerus caffer & 48 & 32 & 11 & 5 & 0.359 \\
\hline Meat & Molola & Canis adustus & 123 & 60 & 58 & 5 & 0.388 \\
\hline Meat & Gewedako & Madoqua kirkii & 93 & 34 & 53 & 6 & 0.425 \\
\hline Berry & K'alahaibe & Opilia campestris Engl & 89 & 29 & 55 & 5 & 0.433 \\
\hline Berry & Kongolobii & Grewia bicolor Juss & 86 & 28 & 51 & 8 & 0.442 \\
\hline Berry & Thakuayabe & Cordia villosa & 65 & 20 & 39 & 6 & 0.446 \\
\hline Berry & Ngwilabee & Grewia similis K. Schum & 74 & 22 & 42 & 10 & 0.459 \\
\hline Berry & Ondoshibii & Cordia gharafEhrenb & 107 & 25 & 70 & 12 & 0.470 \\
\hline Berry & Embelebii & Grewia flavescens Juss & 150 & 20 & 109 & 22 & 0.503 \\
\hline Tuber & Shukumo & Vatovaea pseudolablab & 106 & 27 & 58 & 21 & 0.486 \\
\hline Tuber & Makalita & Ipomoea transvaalensis & 133 & 10 & 105 & 19 & 0.517 \\
\hline Tuber & Matukwayako & Coccinea surantiaca & 144 & 17 & 99 & 28 & 0.520 \\
\hline Tuber & Maqalit'ako & Eminia entennulifa & 72 & 13 & 37 & 22 & 0.531 \\
\hline Tuber & Do'aiko & Vigna macrorhyncha & 152 & 10 & 110 & 32 & 0.536 \\
\hline Tuber & //Ekwa hasa & Vigna frutescens & 196 & 34 & 94 & 68 & 0.544 \\
\hline Baobab & N//obabe & Adansonia digitate L & 160 & 17 & 86 & 57 & 0.563 \\
\hline
\end{tabular}

a Only individuals who were involved in searching for a given wild species were requested to rank the availability of the wild species in question; no wild food was rated "very high (1)" in its availability

"...We do not have much of the wild foods left in this area. If you need such foods, you have to go to great lengths. I do think that with herders and farmers overrunning the land like this, there will be no more wild foods around this area".

Generally, the Hadza face many of the ecological constraints assumed to favour reliance on foraging for household provisioning. Principal factors considered to affect food availability in the order of importance were recurring drought, agricultural expansion, grazing and increased human settlements. Analysis of the household food adequacy shows that the average value for MAHFP in the foraging households was low $(8.4 \pm 1.1)$ compared with the value for the beekeeping $(8.7 \pm 1.6)$ and farming $(9.6 \pm 1.9)$ households $(p=0.000)$.

\section{Food access}

Results of food insecurity access based on assessment of the household's recent experience of food insecurity are presented in Table 4. Except for three indicators (unable to eat preferred foods, eating food individuals do not want to eat, and day and night without food), food

Table 4 Food insecurity related conditions (\%) by main activity of respondents four weeks before the interview

\begin{tabular}{|c|c|c|c|c|}
\hline \multirow[t]{2}{*}{ Condition } & \multicolumn{3}{|c|}{ Household main activity } & \multirow[t]{2}{*}{$p$-value } \\
\hline & Foraging $(n=129)$ & Beekeeping $(n=30)$ & Farming $(n=41)$ & \\
\hline Worried about food & 73.6 & 32.3 & 17.5 & 0.000 \\
\hline Unable to eat preferred foods & 59.7 & 71.0 & 62.5 & 0.508 \\
\hline Ate a few variety of foods & 89.1 & 64.5 & 57.5 & 0.000 \\
\hline Ate food they do not want to eat & 61.2 & 67.7 & 60.0 & 0.766 \\
\hline Ate smaller meal & 72.9 & 32.3 & 17.5 & 0.000 \\
\hline Ate fewer meals in a day & 43.4 & 19.4 & 12.5 & 0.000 \\
\hline No food of any kind in the household & 29.5 & 12.9 & 7.5 & 0.006 \\
\hline Went to sleep hungry & 17.8 & 9.7 & 0.0 & 0.011 \\
\hline Went day and night without eating & 5.4 & 3.2 & 0.0 & 0.301 \\
\hline Food insecure households & 83.0 & 46.7 & 26.8 & 0.000 \\
\hline
\end{tabular}

Differences in percent responses were analyzed using Chi-square test for each of the food insecurity condition at $p<0.05$ 
insecurity conditions varied across household categories $(p<0.05)$; all pointing to unfavourable situation in the predominantly foraging households. Results also show that mean scores of HFIAS for the sample population was 12.1, and there were significant variations of food insecure households between the livelihood options $(p=0.000)$. The prevalence of food insecurity varied with the household's main activity ( $83.0 \%$ foraging, $46.7 \%$ beekeeping and $26.8 \%$ farming).

\section{Dietary diversity}

Results on dietary diversity indicate that respondents consumed between one and eight food groups $24 \mathrm{~h}$ prior to survey with $5 \%$ of the households consuming $\leq 2$ groups of food. Chi-square analysis show that $65 \%$ of households (86\% foraging, $63.3 \%$ beekeeping and $2.4 \%$ farming) consumed $\leq 4$ groups of food $(p=0.000)$. Such individuals consumed mainly roots or tubers, fruits, meat and vegetables. Because distribution of DDS was skewed, median was used instead of mean. The median values of DDS for the foraging, beekeeping and farming households were 3, 4 and 6, respectively. The proportion of respondents having low, medium or high DDS were significantly different between the foraging, beekeeping and farming households (Fig. 1). The Low DDS were mainly

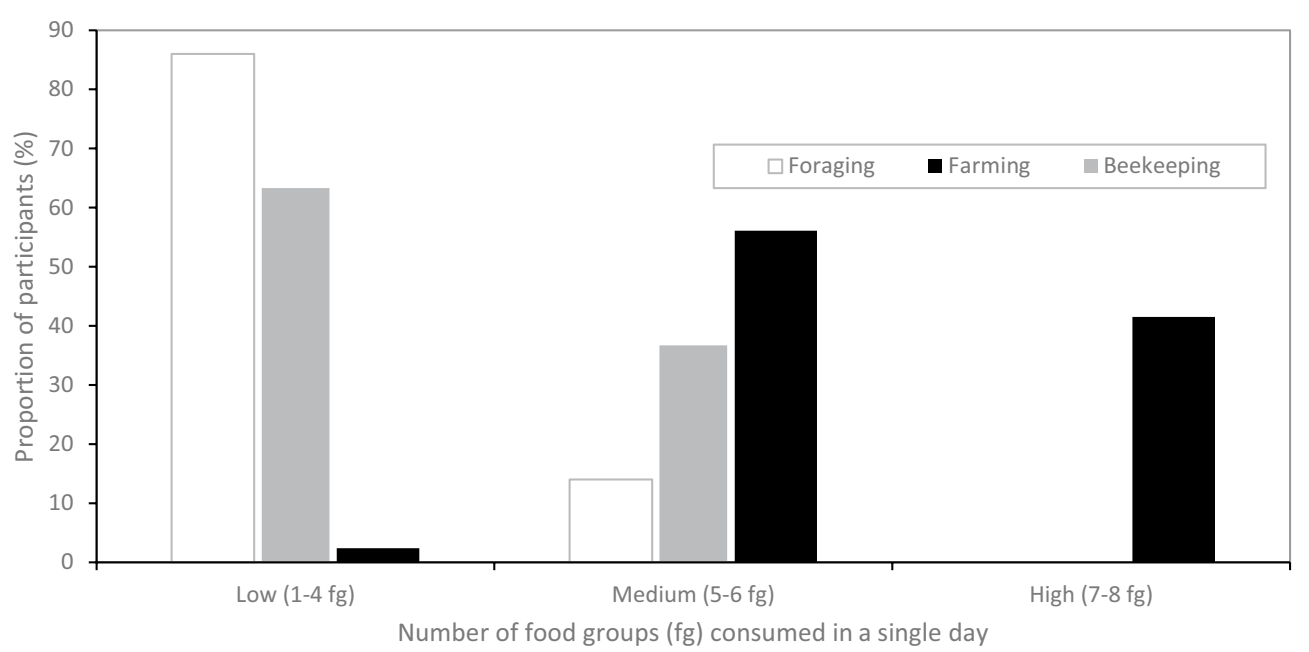

Fig. 1 Proportion of respondents (\%) by Dietary Diversity Score

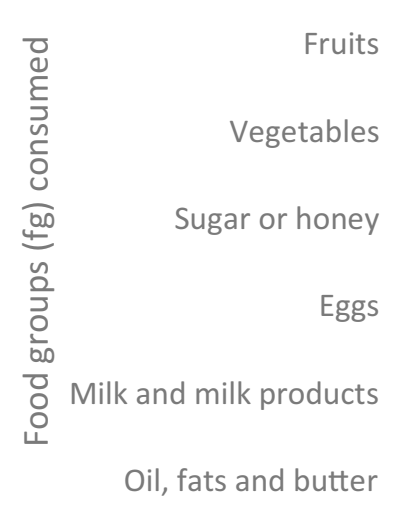

Oil, fats and butter

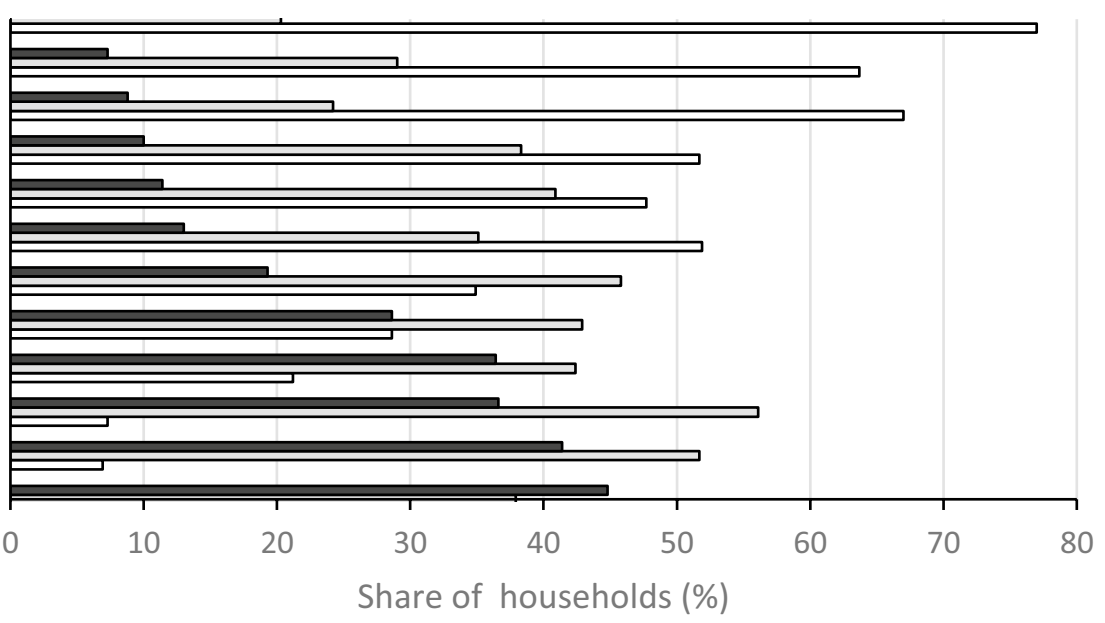

High (7-8 fg) $\quad \square$ Medium (5-6 fg)

Fig. 2 Percent of households consuming each food group as a function of Dietary Diversity Score (DDS) categories 
Table 5 Household Dietary Diversity Scores (DDS) by household characteristics

\begin{tabular}{|c|c|c|c|c|c|c|}
\hline \multirow[t]{2}{*}{ Variable } & \multicolumn{3}{|c|}{ Mean score* } & \multirow[t]{2}{*}{ Total score } & \multirow[t]{2}{*}{ F-statistic } & \multirow[t]{2}{*}{$p$-value } \\
\hline & $\begin{array}{l}\text { Foraging } \\
(n=129)\end{array}$ & $\begin{array}{l}\text { Beekeeping } \\
(n=30)\end{array}$ & Faming $(n=41)$ & & & \\
\hline \multicolumn{7}{|l|}{ Age, years } \\
\hline$<35$ & 5.00 & 5.50 & 6.45 & 6.20 & 18.2 & 0.00 \\
\hline $35+$ & 3.33 & 3.88 & 4.00 & 3.43 & 5.4 & 0.01 \\
\hline \multicolumn{7}{|l|}{ Sex } \\
\hline Male & 3.29 & 3.65 & 6.10 & 3.63 & 96.7 & 0.00 \\
\hline Female & 4.80 & 5.00 & 6.52 & 5.80 & 38.9 & 0.00 \\
\hline \multicolumn{7}{|l|}{ Education } \\
\hline No schooling & 3.40 & 4.00 & 4.00 & 3.51 & 5.6 & 0.01 \\
\hline Formal education & 5.00 & 5.50 & 6.45 & 6.40 & 4.2 & 0.05 \\
\hline \multicolumn{7}{|l|}{ Family size } \\
\hline$<8$ & 3.95 & 4.48 & 6.39 & 4.82 & 130.0 & 0.00 \\
\hline $8+$ & 3.40 & 4.10 & 6.39 & 4.12 & 190.0 & 0.00 \\
\hline \multicolumn{7}{|l|}{ Dependency ratio } \\
\hline$<0.4$ & 3.13 & 6.00 & 6.58 & 5.52 & 209.0 & 0.00 \\
\hline $0.4+$ & 3.44 & 3.96 & 5.63 & 3.65 & 24.9 & 0.00 \\
\hline \multicolumn{7}{|l|}{ Farm size, acre } \\
\hline$<3$ & 3.39 & 3.92 & 6.00 & 3.53 & 22.2 & 0.00 \\
\hline $3+$ & 3.57 & 4.22 & 6.44 & 5.46 & 70.9 & 0.00 \\
\hline \multicolumn{7}{|l|}{ Agricultural tools } \\
\hline No tools & 3.39 & 3.82 & 6.00 & 3.50 & 17.0 & 0.00 \\
\hline Possesses tools & 3.56 & 4.27 & 6.43 & 5.40 & 83.8 & 0.00 \\
\hline Overall mean & 3.40 & 4.10 & 6.39 & 4.12 & 190.6 & 0.00 \\
\hline
\end{tabular}

${ }^{*}$ Means based on 1-12 dietary diversity scales. Dietary diversity scores are significantly different at $p<0.05$

Table 6 Regression summary for predictors of household food security

\begin{tabular}{|c|c|c|c|c|c|}
\hline Variable & B & Std. err & $\operatorname{Exp}(B)$ & Z & $p>|z|$ \\
\hline Household head (above 50 years) & -0.64 & 0.26 & 1.9 & -2.46 & 0.00 \\
\hline Sex of household head is female & 1.13 & 0.51 & 1.2 & 2.21 & 0.03 \\
\hline Household size (below 8 members) & 1.43 & 0.51 & 4.1 & 2.91 & 0.04 \\
\hline Dependency ratio (above 0.4) & -2.16 & 0.77 & 0.1 & -7.86 & 0.01 \\
\hline Farm size (below 3 acres) & -1.97 & 0.67 & 0.1 & -8.59 & 0.00 \\
\hline Household possesses agricultural tools & 2.62 & 0.90 & 13.7 & 8.40 & 0.04 \\
\hline Primary occupation is foraging & -2.37 & 0.98 & 10.7 & -5.82 & 0.01 \\
\hline
\end{tabular}

Number of obs (200), LR chi2 (7), Prob >chi2 $=0.000, R^{2}=0.63$; Exp $(B)$ values are Odds Ratios (95\% Cls)

recorded in foraging households while, the medium or high DDS were largely reported in farming households.

The main food groups consumed varied with low, medium or high DDS (Fig. 2). While more healthy foods including roots/tubers, fruits, vegetables and legumes were consumed more in the low DDS group, less healthy foods such as oil/fats and beverages (coffee or tea) were to a great extent consumed in the high DDS group. Higher DDS was also associated with lower consumption of tubers and meat.
Overall, findings show that the most consumed food group consisted of roots or tubers (78\% of respondents). By contrast, food groups with the low consumption rates were eggs (11\%), oil/fat (15\%), fish (19\%), and milk and milk products (21\%). Results of DDS by household characteristics are presented in Table 5. Significantly low DDS scores were observed in households whose heads were male aged 35 years or above. Analysis also shows that older generations maintained the traditional practices of foraging compared with younger generations. 
Predictors of household food security are presented in Table 6. Of the nine variables considered in the model, seven were good predictors of household food security. These were age and sex of the household head, household size, dependency ratio, farm size, possession of agricultural tools and household main activity. Household headed by persons aged 50 years or older were nearly two times more likely to be food insecure compared with younger counterparts (Odds Ratio$\mathrm{OR}=1.9 p=0.000$ ). Households possessing agricultural tools were more likely to be food secure compared with their counterparts who did not possess the tools $(\mathrm{OR}=13.7 ; p=0.04)$. Food insecurity was associated with smaller farm size $(\mathrm{OR}=0.1 ; p=0.00)$ and foraging $(\mathrm{OR}=10.7 ; p=0.01)$.

\section{Discussion}

\section{Livelihood options}

Results from the present study have demonstrated that households with large family size or high dependency ratio practised farming more than their counterparts. This could possibly be due to increased food requirements in households with these characteristics compared with their counterparts. Results also show higher probabilities of male and older respondents to practise foraging. This tendency could be associated with better hunting skills compared to their counterparts. Previous studies have reported that hunting success generally increases with age in males and peaks in mid-life [39, 40]. However, older people in Hadza community are likely to be at high nutritional risks of long term food deprivation given the unfavourable hunting conditions. Overall, these findings suggest that the Hadza are increasingly practising crop domestication rather than the traditional foraging per se, and are being assimilated into new lifestyles. In this perspective, beekeeping has emerged as an important livelihood option among Hadza. This is consistent with the fact that honey is highly preferred food in the Hadza diet [41]. Not only is this true of the Hadza but also of most foragers [42, 43]. Honey availability helps mitigate food shortages especially during the rainy season when it is more available and hunting is less productive [44].

\section{Food availability}

Analysis of wild food availability shows that tubers form an important part of the diet despite the low caloric value and preference among Hadza hunter-gatherers. Thus, tubers fit the definition of fall back food [41]. Indeed, across much of Africa, underground storage (tubers) of wild plants are considered important energy sources for foragers [45]. This is because wild tubers have several key attributes that make them particularly attractive to hunter-gatherer food especially during the lean season when agricultural products are scarce. One of the attributes is that tubers can be harvested across a greater proportion of the year than many fruits and seeds [10]. Nevertheless, availability of wild food resources is generally under strain, an observation also consistent with previous claims that a Hadza hunter, for example, would go for weeks without making a kill [46]. Various studies have showed that clearing of land for farming, grazing and tree cutting for building and fuel energy are among the major factors for diminution of the wild animal and plant resources which the Hadza have traditionally depended [14, 47]. It has also been established that natural resources dependent societies particularly those living in marginal lands, such as the Hadza, are the most vulnerable and are severely impacted by climate change [48]. Together, these factors have undoubtedly caused a shift away from the diversified traditional food resources making the foraging societies particularly vulnerable to food shortage.

Although the dietary distinction of food items from cultivated and wild resources was not carried in this study, previous estimates suggest that the annual Hadza diet consists of approximately $43 \%$ hunted foods (game animals, birds, and honey) and 57\% gathered foods including fruits, legumes, tubers and nut seeds [49]. These estimates, however, are likely to be higher as data were drawn from Hadza groups living in traditional camps where there is higher dependence on wild food resources than those in sedentary life style. Limited availability of wild food resources as depicted by low indices might explain why some foragers chose to cultivate crops or raise animals, a signal of transition to an agrarian economy. This experience gives a contrasting account of 1925, for example, which explains that the Hadza kept no domestic animals at the time [50]

\section{Food access}

Results on HFIAS measurements suggest that more respondents reported affirmatively to the items indicating less severe food insecurity (e.g. worry, changes in diet quality or reductions in quantity) than those indicating severe food insecurity (i.e. hunger). Overall, findings on the access dimension of food insecurity suggest low economic and physical ability of food acquisition among Hadza. As indicated in Table 4, reliance on foraging reduced access to food compared with beekeeping and farming. The first six items of the scale, which generally reflect less forms of food insecurity and in the last three severest forms of food insecurity were more pronounced in the predominantly foraging households. However, responses to food preference related indicators "unable to eat preferred foods" and "ate food they do not want 
to eat" were not significantly different among foraging, beekeeping and farming households. These indicators suggest insufficient food quality, a domain of occurance of food insecurity which includes variety and preferences of the type of food [32]. Indeed, this observation depicts limited availability of wild food resources which is independent of household's subsisting strategy.

The results have also showed that most severe food insecurity experiences were less reported in farming households possibly because this group had access to a wider range of food resources compared to beekeeping and foraging households. The HFIAS condition "went day and night without eating", a domain of insuficient food intake was independent of the households' main activity. It is the severest condition which rarely occurred across households involved in this study. Generally, access reflects the demand side of food which often indicates uneven household food distribution although food stocks may be sufficient [29]. It also reflects personal and environmental characteristics which can either serve as barriers or enhancements to healthy eating [51, 52]. In this case, it seems that the environmental conditions, for example, are no longer favourable to support optimal foraging activities of the Hadza people as they traditionally did. Current observations are consistent with the findings from a study of 397 in the rural households of Boset district in Ethiopia [53]. Using the same HFIAS categorisation, the authors reported that only $39.8 \%$ of the households were food secure. Similarly, surveys involving 300 households in Mozambique indicated between 20 and $67 \%$ of the households had experienced hunger [38]. These findings show that food access is a concern for most parts in of rural areas of Africa, and more so for those living in marginal areas. The elements in the household food insecurity scale provide important information about household food security across the three major household categories discussed in this study. As the levels of food insecurity conditions were invariably higher in foraging than in beekeeping and farming groups, interventions designed to improve food security should consider strategies necessary to ameliorate differential access to nutritionally adequate food across the groups.

\section{Dietary diversity}

Data on dietary diversity suggest that the Hadza have a narrow base of food production especially in the foraging and beekeeping households. The observed median DDS values for the foraging and beekeeping households are lower than the value of 6 reported in the previous study involving 252 women in three districts of northeastern and central Tanzania [54]. DDS of four has been identified as the critical value below which diet is considered to be nutritionally inadequate $[55,56]$. The inverse association between tubers and DDS could be due to the fact that the Hadza consider tubers a complete meal especially when served with Gisuda, a local alcohol made of honey and plant roots called Teringii. Meat is highly valued, and when available little attention is given to other food groups. It is intriguing to note that fish was consumed by nearly one fifth of the surveyed households. Although in the past, the Hadza did not consider fish as descent food [57]. This aspect of the Hadza culture, therefore, seems to have changed appreciably. In general, these patterns point to relatively low levels of dietary diversity. Indeed, the reliance on starchy foods mainly from roots and tubers with little or no animal products, few fresh fruits and vegetables has been reported to cause multiple nutrient deficiencies [58]. The observed dietary diversity scores imply that supply of important micronutrients in most households was insufficient as dietary diversity measures diet quality and proxy for overall micronutrient intake [59] and nutritional status of individuals [60, 61]. Nutrient deficiencies affect physical and mental development, and such conditions are likely to prevail in the study population.

The observed low DDS among older people may be the result of a combination of factors including reduced physical capacity of old people to procure wild food resources and changes in social and natural environments. It is possible that these factors debilitated access to traditional food resource base. The higher odds of female-headed households being food secure than maleheaded households could be attributed to the social structure. The Hadza exhibit high levels of sexual division of labour, with males acting as primary hunters and females as primary gatherers [46, 62]. On a similar account, hunter-gatherer men have been reported to target high-risk food items that are often characterized by a low probability of success (animal based resources and honey) while women target more stable resources (plant based foods) and typically bring in more calories than men $[63,64]$.

Evidence of higher DDS values among farming households attests to the importance of agriculture in improving dietary diversity and nutrition as reported elsewhere $[65,66]$. It is for this reason that the use of domesticates within a foraging economy has been found to broaden dietary options [10]. Thus, agricultural interventions in the Hadza communities are particularly important. Nevertheless, the role of agriculture has not been sufficient to elevate many Hadza above the threshold of food insecurity. Achieving productivity in growth in agriculture especially in the transitioning of foragers would require development and dissemination of improved technologies. Further analysis on food security reveals that demographic characteristics differ in their effects on the 
probability of households being food secure. The factors presented in Table 6 can be used to predict the state of household food security when designing interventions to alleviate food insecurity in the study population.

\section{Conclusion}

The Hadza hunter-gatherers have adapted a mixed foraging economy with broad dietary options through an array of strategies. Apart from foraging, the Hadza have employed farming and beekeeping as their livelihood options upon which household food security is dependent. All indicators used to assess food security point to a high level of food insecurity in households that subsisted on foraging compared with those which relied on beekeeping and farming. Primary dependence on foraging is associated with a longer period of food shortage, high prevalence of food insecurity conditions and low consumption of food varieties. Factors associated with food insecurity are large family size, owning small farm size and where the household head is male and older. In this regard, provision of agricultural support services is needed to enhance crop production, animal husbandry and beekeeping. Such services should be considered as a high priority need given that the Hadza have limited experience in these activities. It is noted, however, that while this study gives insights on the status and predictors of food security among Hadza, the approach of single-round data does not reflect seasonal variation in dietary patterns. Information on food security across seasons will be required to capture a year-round experience of food security in present-day Hadza communities. Nevertheless, this study provides important information on food security related challenges specific to Hadza-hunter gatherers with a mixed foraging economy.

\section{Acknowledgements}

We gratefully express our appreciation to all of our respondents for participating in this study

\section{Authors' contributions}

JG and AJ conceived, designed the study, collected and analysed data. ZS assisted in writing the manuscript. All authors read and approved the final manuscript.

\section{Funding}

None.

\section{Availability of data and materials}

All the relevant data supporting the findings of this article are contained within the document.

\section{Ethical approval and consent to participants}

Ethical clearance for this research was obtained from the Institute of Rural Development Planning Ethical Review Committee. Permission to proceed with research work was also sought from Local Government Authority in Mkalama District. All respondents gave their informed verbal consent before proceeding with interviews.
Consent for publication

Not applicable.

\section{Competing interests}

The authors declare that they have no competing interests.

\section{Author details}

${ }^{1}$ Moshi Co-operative University, P.O. Box 474, Moshi, Tanzania. ${ }^{2}$ Institute of Rural Development Planning, P.O. Box 138, Dodoma, Tanzania.

Received: 31 July 2020 Accepted: 15 February 2021

Published online: 12 July 2021

\section{References}

1. FAO. The State of Food Security and Nutrition in the World. Building resilience for peace and food security, 2017. Rome: Italy; 2017.

2. Ogundari K. Categorizing households into different food security states in Nigeria: the socio-economic and demographic determinants. Agric Food Econ. 2017;5(1):8.

3. Pérez-Escamilla R. Food security and the 2015-2030 sustainable development goals: from human to planetary health: perspectives and opinions. Curr Dev Nutr. 2017;1 (7):e000513.

4. FAO. The Rome Declaration on World Food Security and World Food Summit Plan of Action. http://www.fao.org/docrep/003/w3613e/w3613 e00.htm, 1996. Accessed 16 June 2020.

5. Warren $\mathrm{E}$, Hawkesworth $\mathrm{S}$, Knai C. Investigating the association between urban agriculture and food security, dietary diversity, and nutritional status: a systematic literature review. Food Policy. 2015;53:54-66.

6. Lang T, Barling D. Food security and food sustainability: reformulating the debate. Geogr J. 2012;178(4):313-26.

7. Gomez MI. A resource inventory of indigenous and traditional foods in Zimbabwe. 1989; University of Zimbabwe Publications.

8. Lee RB. What hunters do for a living, or, how to make out on scarce resources. In Man the hunter, 2017; 30-48. Routledge.

9. De Merode E, Homewood K, Cowlishaw G. The value of bushmeat and other wild foods to rural households living in extreme poverty in Democratic Republic of Congo. Biol Conserv. 2004;1 18(5):573-81.

10. Greaves RD, Kramer KL. Hunter-gatherer use of wild plants and domesticates: archaeological implications for mixed economies before agricultural intensification. J Archaeol Sci. 2014;41:263-71.

11. Lee RB, DeVore I. Man the hunter, 2017; Routledge.

12. Crowther G. Eating culture: an anthropological guide to food. Toronto: University of Toronto Press; 2018.

13. Wood BM, Pontzer H, Raichlen DA, Marlowe FW. Mutualism and manipulation in Hadza-honeyguide interactions. Evol Hum Behav. 2014;35(6):540-6.

14. Woodburn J. Stability and flexibility in Hadza residential groupings. In Man in Adaptation, 2017; 31-37. Routledge.

15. Bleek DF. Bushman occupation in Tanganyika territory. S Afr J Sci. 1931;28(07):423-9.

16. Hawkes K, O'Connell JF, Blurton Jones NG. Hadza women's time allocation, offspring provisioning, and the evolution of long postmenopausal life spans. Curr Anthropol. 1997;38(4):551-77.

17. Kinsella J, Brehony E. Are current aid strategies marginalising the already marginalised? Cases from Tanzania. Dev Pract. 2009;19(1):51-60.

18. Marlowe F. The Hadza: hunter-gatherers of Tanzania. Berkeley: Univ of California Press; 2010.

19. Jones NGB, Smith LC, O'Connell JF, Hawkes K, Kamuzora CL. Demography of the Hadza, an increasing and high density population of savanna foragers. Am J Phys Anthropol. 1992;89(2):159-81.

20. Kusimba CM, Kusimba SB. East African archaeology: Foragers, potters, smiths, and traders. Philadelphia: University of Pennsylvania Press; 2011.

21. Mabulla AZ. Hunting and foraging in the Eyasi Basin, northern Tanzania: past, present and future prospects. Afr Archaeol Rev. 2007;24(1-2):15-33.

22. Wineman A. Multidimensional household food security measurement in rural Zambia. Agrekon. 2016;55(3):278-301.

23. Holt-Giménez E. Food security, food justice, or food sovereignty. Cultivating food justice: Race Cl. Sustainability. 2011;29:309-30. 
24. Ingram J. A food systems approach to researching food security and its interactions with global environmental change. Food Secur. 2011;3(4):417-31.

25. Berbesque JC, Marlowe FW, Crittenden AN. Sex differences in Hadza eating frequency by food type. Am J Hum Biol. 2011;23(3):339-45.

26. Samson DR, Crittenden AN, Mabulla IA, Mabulla AZ, Nunn CL. Hadza sleep biology: evidence for flexible sleep-wake patterns in hunter-gatherers. Am J Phys Anthropol. 2017;162(3):573-82.

27. Kelly RL. The lifeways of Hunter-Gatherers: the foraging Spectrum. Cambridge: Cambridge University Press; 2013.

28. Miah AQ. Applied statistics for social and management sciences. Berlin: Springer; 2016.

29. Barrett CB. Measuring food insecurity. Sci. 2010;327:825-328.

30. Santeramo FG. On the composite indicators for food security: Decisions matter! Food Reviews Intl. 2015;31(1):63-73.

31. Chappell MJ, LaValle LA. Food security and biodiversity: can we have both? An agroecological analysis. Agric Hum Values. 2011;28(1):3-26.

32. Coates, J., Swindale, A and Bilinsky, P. Household Food Insecurity Access Scale (HFIAS) for measurement of food access: indicator guide. Washington, DC: Food and Nutrition Technical Assistance Project, Academy for Educational Development, 2007; 34.

33. Koppmair S, Kassie M, Qaim M. Farm production, market access and dietary diversity in Malawi. Publ Health nutr. 2017;20(2):325-35.

34. Salehi-Abargouei A, Akbari F, Bellissimo N, Azadbakht L. Dietary diversity score and obesity: a systematic review and meta-analysis of observational studies. Eur J Clin Nutr. 2016;70(1):1.

35. Clausen T, Charlton KE, Gobotswang KS, Holmboe-Ottesen G. Predictors of food variety and dietary diversity among older persons in Botswana. Nutr. 2005;21(1):86-95.

36. Coates J, Patenaude BN, Rogers BL, Roba AC, Woldetensay YK, Tilahun AF, Spielman KL. Intra-household nutrient inequity in rural Ethiopia. Food Policy. 2018;81:82-94.

37. Kutner MHNachtsheim CJ, Neter J. Applied Linear Regression Models, fourth ed. McGraw-Hill Irwin. 2004

38. FAO. Report on use of the household food insecurity access scale and household dietary diversity score in two survey rounds in Manica and Sofala Provinces, Mozambique, 2008; http://www.fao.org/fileadmin/ user_upload/eufao-fsi4dm/doc-training/moz_diet.pdf. Accessed 15 June 2020.

39. Gurven M, Kaplan H, Gutierrez M. How long does it take to become a proficient hunter? Implications for the evolution of extended development and long life span. J Hum Evol. 2006;51(5):454-70.

40. Jones NB, Marlowe FW. Selection for delayed maturity. Hum Nat. 2002;13(2):199-238.

41. Marlowe FW, Berbesque JC. Tubers as fallback foods and their impact on Hadza hunter-gatherers. Am J Phys Anthr. 2009;140(4):751-8.

42. Crittenden AN. The importance of honey consumption in human evolution. Food Foodways. 2011;19(4):257-73.

43. Hill K, Kaplan H, Hawkes K, Hurtado AM. Foraging decisions among Ache hunter-gatherers: new data and implications for optimal foraging models. Ethol Sociobiol. 1987;8(1):1-36.

44. Marlowe FW, Berbesque JC, Wood B, Crittenden A, Porter C, Mabulla A. Honey, Hadza, hunter-gatherers, and human evolution. J Human Evol. 2014;71:119-28.

45. Schoeninger MJ, Bunn HT, Murray SS, Marlett JA. Composition of tubers used by Hadza foragers of Tanzania. J Food Composit Anal. 2001;14(1):15-25.

46. Hawkes K, OConnell JF, Blurton Jones NG, Bell D, Bird R, Bird D, Minnegal M. Hunting and nuclear families: some lessons from the Hadza about mens work. Curr Anthropol. 2001;42(5):681-709.

47. Mabulla IA. Impacts of climate change and other factors on Hadza hunter-foragers of northern Tanzania, M.Sc. Dissertation, 2012; University of Dar es Salaam, Tanzania, pp129
48. Lyimo JG, Kangalawe RY. Vulnerability and adaptive strategies to the impact of climate change and variability. The case of rural households in Semiarid Tanzania. Environ Econ. 2010;1(2):89-97.

49. Samson DR, Crittenden AN, Mabulla IA, Mabulla AZ, Nunn CL. Does the moon influence sleep in small-scale societies? Sleep Health. 2018;4(6):509-14.

50. Bagshawe FJ. The peoples of the happy valley (East Africa): the aboriginal races of Kondoa Irangi part II: The Kangeju. J Roy Afr Soc. 1925:24(94):117-30.

51. Andajani-Sutjahjo S, Ball K, Warren N, Inglis V, Crawford D. Perceived personal, social and environmental barriers to weight maintenance among young women: a community survey. Int J Behav Nutr Phys Activity. 2004;1(1):15.

52. Dean WR, Sharkey JR. Food insecurity, social capital and perceived personal disparity in a predominantly rural region of Texas: an individuallevel analysis. Soc Sci Med. 2011;72(9):1454-62

53. Moroda GT, Tolossa D, Semie N. Food insecurity of rural households in Boset district of Ethiopia: a suite of indicators analysis. Agric Food Secur. 2018;7(1):65.

54. Keding GB, Msuya JM, Maass BL, Krawinkel MB. Relating dietary diversity and food variety scores to vegetable production and socio-economic status of women in rural Tanzania. Food Secur. 2012;4(1):129-40.

55. Faber M, Schwabe C, Drimie S. Dietary diversity in relation to other household food security indicators. J Food Saf Nutr Publ Health. 2009;2(1):1-15.

56. Steyn NP, Nel JH, Nantel G, Kennedy G, Labadarios D. Food variety and dietary diversity scores in children: are they good indicators of dietary adequacy? Publ Health Nutr. 2006;9:644-50.

57. Marlowe F. Why the Hadza are still hunter-gatherers. Ethnicity, huntergatherers, and the 'Other', ed. S. Kent, 2002; 247-81.

58. Sunderland T, Powell B, Ickowitz A, Foli S, Pinedo-Vasquez M, Nasi R, Padoch C. Food security and nutrition: The role of forests. Discussion Paper. CIFOR, 2013; Bogor

59. Kennedy G, Berardo A, Papavero C, Horjus P, Ballard T, Dop M, Brouwer ID. Proxy measures of household food consumption for food security assessment and surveillance: comparison of the household dietary diversity and food consumption scores. Publ Health nutr. 2010;13(12):2010.

60. Fujita M, Lo YJ, Baranski JR. Dietary diversity score is a useful indicator of vitamin A status of adult women in Northern Kenya. Am J Human Biol. 2012;24(6):829-34.

61. M'Kaibi FK, Steyn NP, Ochola SA, Plessis L. The relationship between agricultural biodiversity, dietary diversity, household food security, and stunting of children in rural Kenya. Food Sci Nutr. 2017:5(2):243-54.

62. Berbesque JC, Wood BM, Crittenden AN, Mabulla A, Marlowe FW. Eat first, share later: Hadza hunter-gatherer men consume more while foraging than in central places. Evol Hum Behav. 2016;37(4):281-6.

63. Apicella CL. High levels of rule-bending in a minimally religious and largely egalitarian forager population. Relig Brain Behav. 2018;8(2):133-48.

64. Marlowe FW. Hunting and gathering: the human sexual division of foraging labor. Cross-Cult Res. 2007;41(2):170-95.

65. Hoddinott J. Agriculture, health, and nutrition: toward conceptualizing the linkages Reshaping Agric. Nutr Health. 2012;2:13-20.

66. Thompson, B and Meerman, J. Dietary Diversity and Nutrition. In improving diets and nutrition: food-based approaches edited by Brian Thompson and Leslie Amoroso, Food and Agriculture Organization of the United Nations and $C A B I, 2014$

\section{Publisher's Note}

Springer Nature remains neutral with regard to jurisdictional claims in published maps and institutional affiliations. 